\title{
See Spot Run: Movement as an Object of Textual Analysis
}

\author{
Pirkko Markula \\ Jim Denison \\ University of Waikato
}

\begin{abstract}
As physically active people and researchers of physical activity, the authors have trouble translating their movement experiences into words. To them, words seem inadequate for expressing the physical, therefore, "How does one research movement?" The authors first questioned textual representations of movement and sport in a 1996 conference presentation. This article includes their personal movement experiences as a dancer and a runner, respectively, to discuss the nature of contemporary social science research. The authors demonstrate how any experience, not just movement, is always transferred into an object of textual analysis. This conclusion has led the authors to question the privileged nature of language and written research, which they believe turns movement into a disembodied practice. Furthermore, always representing movement experiences with words may mean failing to ask critical questions concerning what it means to be human.
\end{abstract}

Tampere, Finland, July 1, 1996, Crossroads in Cultural Studies Conference...

Pirkko: I am a sport sociologist who longs to move. However, I also enjoy theorizing about the meaning of movement in contemporary Western society, particularly dance. But how does one theorize about movement? How does one write about movement? Can one theorize about movement by writing about it? How do I translate movement into text?

Jim: I am sitting in my office thinking about how to run. It's not something I usually do. That's because I'm a retired runner. I retired in 1991 after a 14-year career. I used to think about running all the time. Now I write about what running means. As a testament to my career, on the bookshelf behind me there is a row of training diaries, 14 volumes arranged chronologically. I'm thinking about running because I am preparing a workshop for a group of triathletes. I'm supposed to teach them how to run efficiently. That is, how to run faster using less energy. They want a handout, too, so they can practice on

Authors' Note: The authors would like to thank Norman Denzin for his excellent editorial advice and guidance in revising this article.

Qualitative Inquiry, Volume 6 Number 3, 2000 406-431

(C) 2000 Sage Publications, Inc. 
their own what I teach them, but I'm stuck. Can I explain in words how to run efficiently? I was just planning to demonstrate and to engage them in some learn-by-doing exercises.

Pirkko: In a recent performance, the choreographer provided us, the dancers, with written notes so we could practice at home. I never used them. I couldn't understand what she meant.

Jim: After a few minutes, I decide that maybe writing is the only way to communicate the physical. So I reach behind me and pick one of my diaries off the shelf. It's 1983, my sophomore year of college. I open it up and begin reading: "April 20, bad day, legs felt heavy, shortness of breath, couldn't move." I turn a few pages: "May 5, Princeton Invitational, ran the 800, a rollover, legs fresh, great kick, shot past three guys in the homestretch as if they were moving backwards." I can also remember the vast assemblage of signs, letters, and numerals my college track coach used to pin on our locker room bulletin board each day, $\left[3(4 \times 400)\right.$ w/1' \& 5' @ 85\% MAX VO $\left.{ }^{2}\right]$. From his scribbled notations, I understood immediately how to move. I often sighed when I read his instructions, knowing that at the end of practice my legs would be aching and my lungs burning.

Pirkko: When I choreographed a duet for an evening of dance I was producing, one of the dancers asked me to write the steps down for her. I refused.

"You have to rely on your movement memory," I told her. "Not a piece of paper."

"You mean this whole routine is in your head?" she asked.

"No, it's in my body."

The same day, I asked another choreographer contributing to the show if he was interested in joining a larger piece that I was also working on.

"Sorry," he said. "I don't have time. I'm too busy working on my own choreography. I want to make sure that I have all the moves written down so my dancers can practice at home."

The next day, a young dancer developing her own solo for the show called me in a panic.

"Pirkko, I've lost the piece of paper where I'd written up my choreography."

"That's okay," I tried to reassure her. "I didn't want to see a piece of paper, anyway. I wanted to see what your dance looked like." She understood that but was convinced that she could not remember anything she had choreographed so far.

"What if I forget a step in the middle of my piece?"

"Improvise," I told her. "The audience will never know."

Jim: I lean back in my chair and think harder about how to run. I realize that I know how it feels to run and what efficient running looks like, but how do I write that down? I open a coaching manual I have had for years and find a definition of running. "The basic running stride may be arbitrarily divided into recovery, driving, and supporting phases," it begins. I read on. "As the 
foot leaves the ground behind the body, the leg flexes at the ankle, knee, and hip joints, the lower leg folds up towards the upper thigh, and the heel rises toward the hip. This shortens the lever of the recovery leg, producing a reduced moment of inertia of the leg rotating about the axis of the hip joint." I stop there. I decide to think some more.

Pirkko: As opening night approaches, we organize a professional film crew to video our performance. I am proud to have this show filmed. When it is finished, I can stack it next to the videos of other performances I have danced in, alongside my dance scrapbook of photos, promotional clippings, posters, and newspaper reviews.

The local city council, who partially funded me to produce this show, questioned me when they saw "video production costs" on my budget.

"How much profit are you expecting from the sale of your video?"

"Nothing," I said to them, aghast. "It's not for commercial purposes. It's for our memories."

Hamilton, New Zealand, March 17, 1999, Pirkko's office...

Jim, how about we send that paper we presented at the cultural studies conference somewhere?

Good idea, where were you thinking?

Maybe Qualitative Inquiry.

They wouldn't be interested. It's too much about movement. How about we send it to Quest?

But it wasn't just about movement, remember. It was about the difficulty of translating experiences, particularly movement, into text.

Yeah, I know, crisis of representation stuff.

Crisis of representation stuff?

You know, the troubles around how to write up lived experience.

But I thought the crisis of representation was about the author's right to represent other people through text- that before, we took it for granted that researchers had the right to write about others and that, somehow, we could do that objectively and accurately. Isn't the whole crisis about when we started to question this right and the meaning of objective research?

Yeah, it is. Ijust frame that problem through language and writing because I see the new ways of writing, like fiction and poetry, that some researchers are turning to as a partial solution to this crisis because those forms allow you to go beyond words, into emotion, into feeling.

Okay, but wasn't our paper about us having a crisis with even those kinds of texts and our inability to represent movement experiences through any kind of language? I thought we problematized the privileged position writing has in academia, either realist interpretations or fictive ones, and how this is really limiting when it comes to writing up movement. 
But is that related to any bigger problem with how we research people and understand experience?

It is. Movement research, which is always written, is an excellent example, don't you think, of the dominance of language. What can be further from language, writing, and text than moving? But still, we always try to turn it into language.

I know. When you really think about it, that's strange.

And I think because our understanding of movement depends on written representations, we've forgotten how it feels to move. So maybe there are all these aspects of movement we're not trying to understand just because we're locked into writing as the only legitimate form of representation?

So what's the alternative, what kind of research are you talking about?

I knew you were going to say that. I don't know. Let me think about it.

\section{BODY-MOVEMENT RESEARCH}

\section{Crossroads in Cultural Studies Conference...}

Pirkko: While physical education, the earliest nominator of any movement discipline at the university, has traditionally consisted of practical-movement education, it also contains rigorous theoretical aspects.

Jim: To achieve the status of an accepted academic subject, physical education had to demonstrate how its knowledge base derived from established scientific disciplines such as biology, physics, and psychology. This led physical education to move away from studying movement as an experience to understanding movement intellectually. Rintala (1991) argues that the so-called science disciplines of movement-exercise physiology, biomechanics, sport psychology, sports medicine, motor learning-intellectualize movement. Many movement scholars argue that this increased intellectual rigor has legitimized the study of physical activity. Others contend that this development marginalizes the body by privileging the mind, and as a result, a separation occurs between the mind and the body.

Pirkko: The separation of the mind from the body permeates our understanding of movement, movement research, and research in general. Most body-mind theorists assign the origin of the concept to the ancient Greeks, particularly Plato. For Plato, every human being existed in a world of Being and a world of Becoming. According to Plato, "one has knowledge about the world of Being; one has opinions or beliefs about the world of Becoming"

(Rintala, 1991, p. 262). We receive knowledge from the everyday world of Being through our bodily senses. However, the body for Plato was "an epistemological deceiver": Its unreliable senses and volatile passions continually trick us into mistaking the transient and illusory for the permanent and 
the real (Bordo, 1993, p. 3). Although Plato provided the starting point for our understanding of the mind as separate from the body, Descartes has probably had the most profound influence on our understanding of knowledge as a deeply dualistic enterprise.

Jim: In Descartes's search for the definition of knowledge, he asserted that knowledge is something that cannot be doubted. Although he could doubt that he had a body, something had to be doing this doubting. Consequently, he could not doubt that he existed as a thinking being. This thinking being, he concluded, must be separate from his body. "For Descartes, the human was some sort of union between the mind as a thinking existence and the body as an extended substance with a mechanical nature" (Rintala, 1991, p. 263).

Pirkko: It is also important to emphasize the hierarchical nature of the body-mind dichotomy: The mind is above and controls the mechanical body. This dualism has had a strong impact on the nature of movement research as the science disciplines attempt to give the body equal status to the mind by intellectualizing movement. They examine the body as a purely mechanical, biologically programmed system that can be fully quantified and controlled (Bordo, 1993). To further the scientific appreciation and analysis of the body, these disciplines have shied away from applied human movement research in favor of examining the smallest fragments of the muscular and neurological systems or conducting animal research.

Jim: Rintala (1991), however, believes that examinations into the meaning of movement conducted by sport sociologists and sport historians have been less impacted by the body-mind dualism embedded in scientific inquiry as they focus not on movement and the body itself but on the structures in which humans act.

Pirkko: But we are not so sure we agree. For example, after years of neglect, the body has recently emerged as a fashionable topic for social analysis. One central characteristic of human movement is corporeality: The body is the instrument of dance; the body executes the beauty and pain of running. However, have these sociocultural studies of the moving body intellectualized the study of movement any less?

Jim: Anthropologist Paul Stoller (1994) notes that much has been written about body-centered phenomena. These scholarly analyses, like our everyday attempts to deal with movement, Stoller contends, have focused on transforming figurative experiences into text and language.

Pirkko: For example, most dance sociologists and sport sociologists focus on the discursive analysis of the dancing, exercising, and sporting body in contemporary society (e.g., Adair, 1992; Birrell \& Cole, 1994; Cole \& Hribar, 1995; Cooper Albright, 1997; Daly, 1992; Davis, 1997; Dempster, 1988; Desmond, 1994; Duncan, 1990, 1994; Foster, 1986; Hall, 1996; Kagan \& Morse, 1988; Koritz, 1996; Lenskyj, 1998; Loy, Andrews, \& Rinehart, 1993; Maguire \& Mansfield, 1998; Markula, 1995; McKay \& Middlemiss, 1995; Messner \& Sabo, 
1990; Pirinen, 1997; Sherlock, 1991; Theberge, 1991; Thomas, 1996; Trujillo, 1995; White \& Gillett, 1994; Yeates, 1995).

Jim: These scholars either examine the body as a social phenomenon embedded with dominant ideologies, like any other facet of present-day culture, or they analyze the body as discursive-an object with markings of powerful disciplinary practices. Such analyses, like the reading of any text, decode the cultural subtext of movement in the body. As dance sociologist Joyce Sherlock (1991) explicitly acclaims, "Today many recognize that art [dance] . . . signifies and is read" (p. 546).

X-Sender: pmarkula@mailserv.waikato.ac.nz

Mime-Version: 1.0

Date: Thu, 18 March 1999 05:55:36

To: jdenison

From: Pirkko Markula waikato.ac.nz

Subject: writing movement

Hi Jim,

I have been thinking about our discussion yesterday. I had some more ideas about our paper.

Obviously when we teach, perform, coach or remember movement, we need to read about it and write about it. But translating movement into words is an arduous process. I think one difficulty is converting movement sensations that all happen simultaneously into a logical succession, a basic requirement of comprehensible writing. Consequently, written descriptions of movement techniques become cumbersome. For example, the description of the running stride that you encountered was unintelligible. obviously, one way we try to overcome this ambiguity is by coding movement into a series of symbols where one symbol contains a wealth of movement information. Like your coach's workouts resembled mathematical equations. But through coding our movement experiences, I think, we only capture fragments of them.

Textualizing movement is especially relevant for us because writing is so privileged within academia. In order to legitimately examine movement, we turn it into a collection of carefully labeled textual objects. In other words, to research movement, it has to be transformed into a text that can be analyzed . . . quantitatively OR qualitatively. 
But the difficulty with examining movement this way is that it is elusive. . . here one minute and then gone the next. For example, my dance performance occurs and it cannot be seen again until the next show. Or following a running race or some other sport event what is there left for you to remember? The event is over. . . it's gone. But then why do we need to remember? What are we so afraid of forgetting? Movement is ephemeral but somehow we cannot accept its evanescent nature. That's why we try to capture it in words or on film instead of simply letting it go or creating new movements.

Anyway, I think I had a breakthrough in thinking about this in more theoretical terms. I was reading a book by James Clifford, who drew on Jameson's use of a semiotic square to draw a map explaining the relative value of ethnographic collections. He derives from Jameson's notion of the presentation of concepts as a semiotic square because it reveals "the limits of a specific ideological consciousness, [marking] the conceptual points beyond which that consciousness cannot go, and between which it is condemned to oscillate" (p. 47). So, I drew a diagram to show how movement becomes research given the present ideological context of useful research. I think it illustrates our case quite well. I'll print out the diagram and a draft of how I apply it to movement research. I'll put them in your pigeonhole.

Pirkko

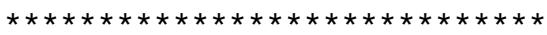

\section{Elusiveness of Performing Arts}

Although the evasiveness of movement troubles many researchers, some theorists see this as the defining characteristic of performing arts like dance. In dance, we often consider ourselves creating art that only actualizes in the context of performance. McFee (1994) argues further that to speak of perform- 
ing means an implicit contrast between the performing arts and the visual arts. He bases his argument on two characteristics of the performing arts. First, the idea of performing arts implies the possibility of a number of performances. Unlike visual arts, performing arts are elusive: “They must be brought into completeness-as the name suggests-by being performed" (p. 89). Second, the work of performing arts is only encountered when one attends a performance. One is never, McFee theorizes, "confronted by a work of art when one confronts a notated score or a film or a video" (p. 88). Therefore, dance, like the other performing arts-music and drama-occurs in a particular moment, in the flow of time.

Phelan (1993) labels this flow of time found in dance ontology of performance. The only life of a performance is in the present, she argues. "Performance occurs over a period of time which will not be repeated. It can be performed again, but this repetition marks it as 'different'" (p. 146). Although evanescent, a work can be performed repeatedly. Every performance, however, is a different interpretation from the previous one. Clearly, if there is no performance, dance does not exist. It was, however, important for Pirkko to restore her performances in videotapes. If the context of elusive performance is defining dance so exclusively, why then carry it away in a videotape? To understand Pirkko's need for videotaped dance, we want to draw a perhaps unlikely parallel between dance and ethnography.

\section{Diagram of Movement Research ${ }^{1}$}

Kirschenblatt-Gimblett (1998) talks about ethnographers who, in the same way that Pirkko creates videos of her performances, detach objects from their original context and carry them away to be exhibited in museums as cultural artifacts. Obviously, it is more difficult to salvage ephemeral experiences like dance performances or rituals, but it is possible to store them in notes, recordings, photographs, films, or drawings that, when needed, one can look at again. Although such documents might not be as tangible or real as artifacts commemorating an event or culture, such inscriptions, however mimetic or representational, are indeed concrete, like objects that we can look at time after time. These visual mementos of movement, then, become objects that can be possessed. Through such objectification, we transform the temporality of movement into real time and give it a history, a present, and a future (Clifford, 1988), which in turn gives value to our movement experiences. Instead of leaving movement to come and go, we turn it into something collectable like notes, diaries, videotapes, posters, newspaper stories, or photographs. Pirkko dutifully collects dance posters and performance videos to have her achievements visibly assembled. Jim has meticulously accumulated rows of diaries to restore his whole running career. However, objectifying our memories is a selective process, says Clifford (1988). For example, most of the photo- 
graphs in our albums depict significant moments in our lives, and usually happy ones. We encounter smiling faces from graduations, birthdays, Christmas holidays, or weddings instead of our office, arguments, meetings, cooking, or cleaning the house. In this way, Pirkko's dance videotapes do not contain rehearsals or her grimacing over her sore knee. Her collection of dance videotapes demonstrates carefully selected series of performances with completed choreography, made-up dancers in full costume, and the near-perfect execution of music and movement. Likewise, Jim's lengthiest diary entries follow a race. Here he recounts in detail the specifics of what happened during a particular race, including intermediate times, the weather conditions, his impressions of how the race developed, and the full results with each competitor's official time.

Therefore, like ethnographic exhibitions at museums, Pirkko's videotapes and Jim's diaries represent movement detached from its performance context. Kirschenblatt-Gimblett (1998) also notes that in museums, ethnographic objects become fragments of culture that through exhibitions display their culture of origin in a way that the museum curators and museum visitors envision it. This is where Clifford (1988) connects our obsession with collecting cultural artifacts to a larger concept of Western identity.

Clifford (1988) argues that collecting in the West gives individuals distinct identities; that is, collecting creates cultural selves. For example, when collecting artifacts for museum displays, ethnographers create ethnography as a discipline and establish themselves as practitioners of this discipline. Like ethnographers, we too objectify and fragment our movement experiences into collections to create identities for ourselves. Jim's collection of running diaries enables him to define himself as a competitive runner, and Pirkko's collection of dance videotapes gives her an identity as a choreographer. Collecting, according to Clifford, at least in the West, has long been "a strategy for the deployment of a possessive self, culture, and authenticity" (p. 218). He adds, "in the West, where time is generally thought to be linear and irreversible, artifacts and customs are saved out of time" (p. 231). This need to restore the past through collections may be fundamentally embedded in our Western culture. Kirschenblatt-Gimblett (1998) observes further that we often classify our collections using text. This means that objects no longer have value without an accompanying text. Textual labels or explanations define the objects' place in a collection hierarchy. In addition, as collected objects are detached from their original context, textual labeling recreates their context for us. Therefore, language is an integral part of a proper collection.

Language is also important when we consider academic collections. Academic research, like ethnographic research, can only be understood as collections of objects when they are labeled. Such collections become meaningfully marked as research objects or scientific evidence only when they are included within the context of scholarly research through the proper use of language, otherwise they are dismissed (Baudrillard, 1997). Therefore, one has to 
objectify experiences to research them. Moreover, collections of objects (data) have to be labeled to be considered legitimate. After this, we can write about our data collections.

We have argued earlier in this article that movement experiences must be textualized to count as objects of research. Therefore, it appears to us that, like the scientific studies of movement, these sociocultural accounts also intellectualize movement and privilege the mind. Because movement experiences translate into texts with difficulty, we analyze them through videotapes, written accounts, or the cultural subtext of the body. As Plato did, we mistrust our sensory movement experiences and prefer to intellectualize these experiences through a cumbersome process of objectification and textualization. Treating text and language as cognitive, as being in a mind realm, makes them seem more worthy of academic analysis. This notion has become so taken for granted that we seldom question the limitations of textual analysis. As a result, we continually produce disembodied texts.

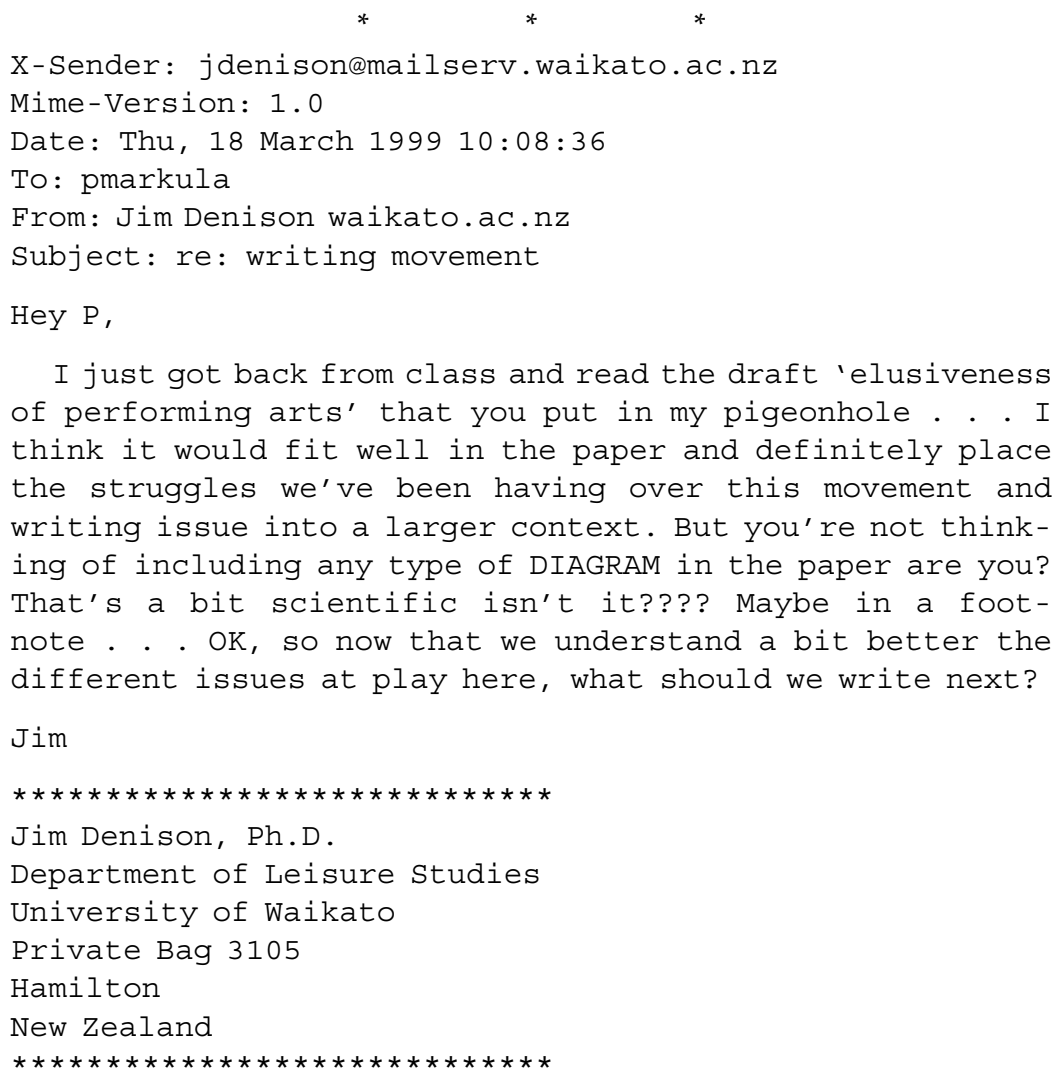




\section{REEMBODYING THE SCHOLARLY ENTERPRISE?}

One person who has remarked on the disembodied nature of textual analyses of the body is Connerton (1989). He points out that although discursive analyses reveal important aspects of movement, they also limit our understanding. Connerton argues that these analyses reveal only one aspect of our social memory. He says that we remember only partially through cognitive memory, through reading not only written texts but also the texts contained in photographs, books, audiocassettes, videocassettes, and movies. He labels this type of memorizing inscription. Stoller (1994) expands on this idea: "Most scholars of social phenomena have privileged practices of inscription. Inscription can be analyzed discursively-as texts, extending metaphorically even to cultural markings on the body" (p. 639). Furthermore, Connerton (1989) argues that inscriptions and, hence, texts have become privileged objects of interpretation in the social sciences "because the activity of interpretation itself has become an object of inspection, rather than being simply practiced, in a particular context" (p. 96). Stoller, however, argues that many attributes connected to bodily sensations in our everyday life, such as the colors and smells that surround us, have been excluded from academic research in favor of textual analysis.

\section{From Inscription to Incorporation}

Following Connerton's (1989) call for increased corporal analyses, Stoller (1994) recorded bodily experiences while studying the spirit possession ceremony of the Songhay people of Niger and Mali. He opens his article by touching on various senses like smell, "the acrid smell of burning resin," sound, "the resonant clacks of bamboo drumsticks striking gourd drums," and sight, "the four mud-brick houses" (p. 634), to present spirit possession as an "embodied phenomenon" (p. 636). Although we do not actually smell the smells he does, hear the sounds he does, or see what he sees, by bringing attention to these qualities, he adds fullness and life to his writing. Stoller's writing is also emotionally evocative. The verbs he uses in the first two paragraphs, "lingered," "dissipated," "crackle," "shimmer," and "clustered," slow down the action and draw out the proceedings. This creates a suspenseful mood and intensifies the feelings of fear and uncertainty that we imagine Stoller must be experiencing as he witnesses the spirit possession ceremony unfold. Later on, he makes sharp cuts from speech to description, and his clipped sentences speed up the story, which effectively keeps us in the dark, possessed, just as he is, by the mystery of this ceremony and the mystery of this culture. His work, therefore, can be appreciated beyond an intellectual level as he attempts to present embodied subjects. Stoller also conveys actual 
living, moving bodies. Unlike most ethnographers who present static and flat representations of people, he allows us to hear his subjects, "Hauk'ize of Tillaberi, present yourselves for our roundtable," to watch them move, "slowly the nonpossessed men and women form a loose circle around the deities," and to see how they look, "Mounkaila, a tall wiry man" (p. 634). This gives Stoller's writing energy and vitality. Through the way he chooses to write up experience-vivid descriptions, emotional language, specific images-we get a sharp picture in our mind of human beings interacting and experiencing life.

In a similar way, a number of evocative interpretations of sport are filled with Stoller's (1994) notion of incorporated writing. Tiihonen (1994) transmits a telling image of what it is to play sport with asthma: "My legs give way. Vision clouds.... Over the toilet bowl and hacking. Not just a hack... Tearing lungs.... I'm faint" (p. 51). Using short sentences and relying heavily on verbs and nouns, he creates a sense of urgency and speed to his description. His writing has a powerful emotional effect as we worry if he will be all right. His writing is also very sensual—"vision clouds," "hacking" —which gives us a deeper understanding of the situation he is in and how a body reacts in distress. Furthermore, we can place him, "over the toilet bowl," and begin to formulate a picture in our mind that results in a vivid image of a human being experiencing life. In the opening to his fictional ethnography on skateboarders, Rinehart (1998b) captures beautifully the body moving through time and space:

He dropped in smooth-like off the slanting concrete, took a quick last puff, then tossed his Marlboro aside and went for the grind ... to get good air, to ascend magically up to the slight rise of the coping, he timed the heel and toe pops just right, carrying the board, no hands, up with his jumping body. (p. 55)

These sentences have a languid, drawn-out feel. They remind us that our bodies are not short and angular but long, curved, soft, and round. He allows us to experience and witness limbs extending and torsos stretching. Denison (1996) also wrote up sport experiences in an evocative way when he studied how athletes experience retirement from highly competitive sport. To open the dimension of mystery that surrounds athletes' retirement experiences and to convey a mood of uncertainty and unease, he allows us to hear his subjects talking to themselves. We sense Steve's confusion, an aging, longdistance runner in the middle of a race, when he wonders, "Am I getting too old? What else can I do?" (p. 352). Furthermore, when Sarah, a former Olympic cyclist out on an easy morning ride, realizes that speed and efficiency are suddenly unimportant, there is a tinge of anxiety in her voice when she asks herself, "What do other people think about during their rides?" (p. 353).

However, following their rich descriptions, Stoller (1994), Tiihonen (1994), Rinehart (1998b), and Denison (1996) all revert to traditional social-science 
speak, which is heavy on referencing, passive verbs, and grand theorizing. Their foray into what Stoller calls incorporated writing is brief. Furthermore, it is difficult to know how their writing really classifies as incorporated. Stoller in particular criticizes a number of articles and anthologies that analyze the body for failing to move beyond the body-as-text metaphor. He believes that topics such as diet, consumer culture, and aging are "worthy of an embodied reformulation" (p. 637). However, he never provides a specific explanation of how this should be done. He does not mention one writing practice or technique that might help us create embodied texts. Although it might be true that his writing is filled with smells, textures, sights, sounds, and tastes, he has still turned experience into an object of analysis. Through words and scenes that are vivid, descriptive, and emotional, he has given us a thicker image of human experience to picture in our mind, yet this image is still an objectified experience.

Rather than being incorporated, we might argue that Stoller's (1994) account, as well as Tiihonen's (1994), Rinehart's (1998b), and Denison's (1996), are visceral; that is, they go beyond conscious reasoning and bring us inside experience and in touch with feelings. They are closer approximations of lived experience, which give them greater credibility and authority as a realistic account. For as Denzin (1997) says, "Seeing is not understanding. Understanding is more than visual knowledge. Understanding is visceral" (p. 46). However, even the best visceral writing is not the experience itself. Therefore, we do not find that by simply including descriptions of smells, textures, sights, and sounds, Stoller (1994) overcomes the problems associated with the body-as-text metaphor. However, Pollock (1998) contends that through performative writing, it is possible to go beyond textuality. By practicing performative writing-“shaping, shifting, testing language" (p. 75)-she claims that she can "bring the reader into contact with other worlds ... that are other-wise intangible and unlocatable" (p. 80). She contends that it is possible to create texts in which the "writing performs: challenging the boundaries of reflexive textualities" (p. 75). She is interested, therefore, in the same issue we are: how to write or conduct research in a way that does not always turn experience, in our case physical activity, into an object of analysis. Therefore, we turned to her work as providing possible strategies for creating truly embodied texts.

\section{Performative Writing}

Performative writing, Pollock (1998) claims, involves six qualities. It is evocative, metonymic, subjective, nervous, citational, and consequential. By evocative, she means writing that includes "worlds of memory, pleasure, sensation, imagination, affect, and in-sight" (p. 80). She advocates using descriptive prose that allows alternative views to come in and be heard, thereby 
enabling various interpretations. Writing metonymically is dramatizing the limits of language by allowing a related linguistic symbol to represent the things that are meant. For Pollock, this technique brings more attention to the material world because it recognizes what writing displaces. The result is an unwriting or undoing of that written object, thus revealing its truth. By subjective writing, Pollock means writing that does not circle "back on the writer/subject in such a way as to enclose the 'self' ... as is the aim of the conventional autobiography" (p. 86). She is opposed to any fixed notions of the self; therefore, she advances ways of writing that problematize subject selves and subvert a humanistic representation of individuality. She believes that this can make one's writing embodied and thus nontextual. For Pollock, performative writing is also nervous, in which time is in flux and the text does not operate in a conventional, straightforward manner. She calls for writing that is busy, moving, and restless, like the synaptic relay that is continually charging through us. Because at some level we are always moving, twitching, and flinching, writings on the body should also be jittery or dizzying. This sort of electric prose about the body, she believes, offers the possibility of presenting it whole. Pollock is keenly aware that texts are always an interpretation of experience and that they are always a few steps removed from raw experience; therefore, she argues for writing that is citational. This sort of writing on writing, or a metadialogue of the body using notes and references, she believes, will enable us to reveal the prewritten qualities of the body. Pollock's final criterion of performative writing, consequential writing, exposes the borders and boundaries that separate us and then intentionally blurs them. Consequential writing, she argues, contests how language constitutes life.

Although Pollock's (1998) list of strategies can certainly help us to produce richer and more descriptive writings, we still interpret them as being textual strategies. Therefore, we wonder how her suggestions actually transcend the body-as-text metaphor or lead to more incorporated ways of knowing and understanding the human experience. For example, writing evocatively as a way of opening up texts to more than one interpretation is a strategy that many qualitative researchers have been practicing for years. In a narrative of self that is both uplifting and disturbing, Sparkes (1996) explores his own interrupted-body project. Through highly personal accounts that are provocative, emotionally charged, and performative, he claims that we will better understand the "reflexive relationship between the body and self over time" (p. 463). Bruce (1998) justifies writing experimental research stories because they create "possibilities for new insights" (p. 3). Tsang (2000) uses self-narratives to represent her experiences within high-performance sport because they allow for "ambiguities to surface and for contradictions to coexist" (p. 45).

Similarly, scholars from most every discipline have been writing subjectively and placing the self in flux for years. Listen to the way that Sudwell 
(1999), a sport psychologist, speaks to his relationship to his father through changes in his own body:

I remember finding an old picture of my father when he was nineteen or twenty, stood on top of a diving board: it could have easily been a photo of me. For months I carried it around in my pocket, showing it to everyone I knew. I was everything he was. (p. 20)

Sudwell attempts to make sense of himself given his multiple subjectivitiesman, son, English, working class, athlete. Sudwell's statements, "it could have easily been a photo of me" and "I was everything he was," could easily be understood as questions that he is asking himself, us, or his father. Thus, the passage rings with a sense of ambiguity, as these are unanswerable questions of identity and unstable selves.

Pollock's (1998) practice of nervous writing, writing that does not "settle into a clear, linear course" (p. 90), is more a metaphor for writing about the body. It still leaves us with a representation of it. For example, in his award-winning fiction, Wallace (1999) does a brilliant job at showing how fear shoots through a 13-year-old boy on his birthday as he makes his way up a high-diving board for the first time:

The rungs are very thin. It's unexpected. Thin round iron rungs laced in slick wet Safe-T felt. You taste metal from the smell of wet iron in shadow. Each rung presses into the bottoms of your feet and dents them. The dents feel deep and they hurt. You feel heavy. (p. 9)

Wallace's writing rips into experience with a disquieting calm that escalates into almost unbearable tensions. It is sensual: the taste of metal, the smell of wet iron, and the dents in his feet. Without commas and with a succession of short, hard sounds, "rungs," "iron," "dense," "heavy," and "hurt," Wallace elicits from his description the pain, confusion, and newness that accompany the change into adolescence. His writing is highly emotional. We see and feel hormones zinging through this boy. However, it is a picture in our minds with a sense of believability and partiality that we accept.

We are also skeptical about Pollock's (1998) reference to citations as a strategy to reveal the prewritten qualities of the body. In our view, writings about writing, as Barth (1956) does in the following passage when he reveals through parenthetical statements his writing and thought processes in creating his character Todd Andrews- "I look like what I think Gregory Peck, the movie actor, will look like when he's fifty-four, except that I keep my hair cut short enough not to have to comb it, and I don't shave every day (the comparison to Mr. Peck isn't intended as self-praise, only as description. Were I God, creating the face of either Todd Andrews or Gregory Peck, I'd change it just a trifle here and there.)"-if anything emphasize the power that language has in constructing experience and creating a sense of the real. 
Many feminist writers (Krieger, 1991; Lather \& Smithies, 1997; Trinh, 1989) have utilized Pollock's (1998) strategy of writing that is consequential and forceful and that makes a difference by contesting how language constitutes life. Richardson (2000) calls these messy, mixed-genre texts. As Richardson says, by revealing the borders and boundaries that separate us and intentionally blurring them, these "writer/artists roam freely around topics, breaking our sense of the externality of topics, developing our sense of how topic and self are twin-constructed" (p. 14).

Pollock (1998) concludes her essay with a brief passage illustrating how she combines these six qualities to create a text that performs and makes writing meaningful—writing that "recognizes its delays and displacements while preceding as writing toward engaged, embodied, material ends" (p. 96). Collectively, these techniques, she maintains, bypass "both the siren's song of textual self-reference and the equally dangerous, whorling drain of unreflexive commitment. Performative writing takes its energy from that refusal, and from the moment when such apparent contradictions surge into productivity" (p. 97). We agree that Pollock's concluding passage shows imagination, includes affect, incorporates linguistic images and symbols to portray the corporeal, and places the self in a state of flux. However, she still preserves experience in words and thus only captures fragments of these experiences. Her writing techniques definitely transgress the boundaries of traditional social science writing genres, but they do not go beyond textuality. They are stocked full of meanings that are tangible and locatable. Rather, we are more convinced by Rinehart (1998a), who argues that evocative or subjective ways of writing cannot bring experience alive in social science writing. These practices will not uncover or reveal concrete, material, or missing bodily forms. Writing always produces a certain kind of truth, a truth that is always textual. Raw or bodily experience, he contends, "comes at a rush. It is only after the effects of life have washed over us that we reconstitute them as belonging to this or that category" (p. 201).

\section{Bodily Writings}

Although we find Pollock's (1998) suggestions to be limited to advice for good writing, we do consider her aim, writing that goes beyond textuality, fascinating - in particular, her notion of tapping into some prewritten quality of the body. Other researchers have also advocated the idea of prelingual, bodily knowledge. One of the first was Langer (1953). The central argument of her theory of art as a symbolic form was that all humans attempt to understand and express their surroundings through symbolic forms like religion, science, or art. These symbolic forms give meaning to the world around us. Dance as an art form, Langer believed, constituted such a symbolic form. For 
her, dance and the body as its instrument, occupied a privileged position as it was the most primitive and natural way of expressing one's thoughts and feelings, predating the development of language, art, and science. Although today the meaning of dance might be less primeval, the body still remains a natural instrument for expressing emotions. Physical expression is still considered by many to be the most appropriate way of expressing feelings that are indescribable through language. This conception of the body as prelinguistic, as outside language, has become known as the natural body.

Langer's (1953) theory created dance as a privileged site of knowledge, and not surprisingly, many dance researchers used her work to justify dance as an academic subject. Whereas some researchers still view the body and dance as a means to communicate abstract feelings (Blumenfeld-Jones, 1995), most have strenuously pointed out the limitations of a theory of the natural body (e.g., Adair, 1992; Cooper Albright, 1997; Foster, 1986, 1995; Novack, 1995). These critics contend that Langer's argument was based on an essentialist assumption of a natural body that we all possess deep down under the covers of civilization. As a result, dance as a natural bodily practice can reveal our true selves - the essential, prelingual self unspoiled by civilization-in ways that speech or language cannot. This position gives dance the status as an outlet for intuitive, unconscious emotional states that are inaccessible through verbal (intellectual) expression (Adair, 1992; Foster, 1986). However, according to Foster (1986), the quest for a natural body also leads dancers and dance researchers to "cultivate a sanctimonious mutism, denying what is verbal, and discursive in order to champion the physical and the sensate" (p. xiv-xv).

In her work, Novack (1995) demonstrates how the notion of a prelingual body can perpetuate the body-mind dualism instead of providing us with new valuable knowledge. According to Novack, Anna Halprin's work on spontaneous ritual embeds a trust of a prelingual body. Halprin's work emphasizes how participants can, through listening to their bodily feelings, reconnect with the earth. During spontaneous rituals, she urges her participants to abolish any thoughts and simply focus on the body's feelings. As the ritual aims to tap into bodily feeling, talking is discouraged. Although Novack does not deny that the participants in such rituals might feel exhilarated, she sees these rituals as advocating an "underlying wisdom of the natural body" that "is thought to be recognized and followed, freed of dominance by the artificial mind" (p. 178). Like Langer's (1953) theory, such rituals promote bodily knowledge as essential, as more true and original than any other knowledge. Although this call for forgotten bodily knowledge can be understood as a reaction to logocentrism-the world where the mind is privileged-it, instead of challenging the body-mind dichotomy, actually perpetuates the dualism by unreflexively privileging the body. Therefore, the search for original, true knowledge contained in bodily movement is the 
reverse of the overly theoretical, textual studies that privilege the mind as the creator of knowledge. Novack concludes, thus, that the notion of a natural body permeates "the view of body/emotion and mind as separate and antagonistic" (p. 179).

The recent popularity of textual interpretations of dance and the dancing body can also be understood against the notion of the natural body. Feminist researchers challenged the idea of a natural body by following a central argument in feminist thought: Women's oppression is naturalized by linking femininity with nature and the body. To challenge this connection, feminists demonstrated that women's inferiority is socially constructed based on socially constructed ideas about the natural feminine body. As a consequence, the dancing body was also understood as a social construction that, far from being natural, was shaped to represent a certain kind of femininity. As discussed earlier, the notion of the body as entirely socially constructed can also be misleading as it ignores important aspects of bodily experience and thus unfairly privileges the mind. Until recently, feminist dance researchers have been reluctant to focus on the physical aspects of dance-the dancing body or dance movement - to avoid perpetuating an oppressive notion of women as naturally bodily. Recently, however, numerous voices have been calling for a combined understanding of the cultural construction and the physical experience of dancing. Among these voices is dance historian Susan Foster (1995). In many ways, Foster's thesis resembles Pollock's (1998) aim to go beyond textuality.

Foster (1995) argues not for the exclusion of the body or of writing but for different, more embodied ways of research that would reinvigorate the previously rationalistic scholarly discourse on bodily expression. For Foster, it is still important to acknowledge that the body is socially constructed and thus communicates social meanings. However, it is equally important for her to consider the body's unique ways of communicating through movement. For Foster, this is possible through kinesthetic empathy. She argues that we all have the ability, proprioceptively, to connect with another person's bodily feelings. In this way, bodies can communicate their inner workings to each other. When entering into such a bodily dialogue, literally or imaginatively, the result is a text that is teoric, that is, both theoretical and performative. Approaching research kinesthetically, Foster feels and ensures that movement is not only read but that the body itself enacts meaning. To ascertain this corporeal writing, writing that includes the body's ability to write, it is important to continually ask what can be written about the body and what can be moved about the body. The result of this continual dialogue is an advanced narrative form she calls moving writing. Foster emphasizes, however, that the body can never act as a subject for research because it is always a product of its social markings and thus an object for a textual reading. In her own research, Foster maintains a dialogue between the body that writes (herself) and the 
other dancing and researching bodies that are written but at the same time also write. To create kinesthetic empathy with the reader, she includes in her research frequent descriptions of the act of writing, including the physical labor and bodily feelings:

Sitting in this chair, squirming away from the glitches, aches, low-grade tensions reverberating in neck and hip, staring unfocused at some space between here and the nearest objects, shifting again, listening to my stomach growl, to the clock ticking, shifting, stretching, settling, turning-I am a body writing. I am a bodily writing. (p. 3)

The reader can thus enter into a kinesthetic dialogue with Foster's bodily writing process. Simultaneously, Foster's body is actively enacting meaning through this description: "I am a bodily writing." Foster also underlines the conversational nature of her writing by alternating between normal text and bold-faced text, as if to visibly engage different bodies into the dialogue. Moreover, the actively conversing body becomes a central creator of the research process as the body becomes her metaphor of the research act.

Foster (1995) concludes her article with bodily musings that, much like Pollock's (1998) conclusion, aim to demonstrate moving writing in action. Foster envisions Clio (the muse of rhetoric) and Terpsichore (the muse of dance) engaged in the spontaneous process of choreographing a postmodern duet. Both muses contribute equally as they react, derive, complete, or feel each other's movements.

I can see them now, Clio and Terpsichore, costumed in their combat boots and high-top sneakers, their lycra tights and baggy trousers, a leather jacket, a vest, under which can be glimpsed unshaven armpits, perhaps even a bow tie or some plastic bananas as a hairpiece.... I can feel them spinning, lurching, sidling and smashing up against one another, laughing knowingly as they wipe the sweat off foreheads and from the skin between lips and nose.... This duet rejuvenates itself endlessly. It has an insatiable appetite for motion. (p. 20)

Foster's researcher body feels the sisterhood of the two muses through her kinesthetic empathy. Through their moving bodies, the reader can also feel, engage, and move writing to initiate new directions for movement research.

Apparently, Stoller (1994), Pollock (1998), and Foster (1995), like us, find that textual research only addresses selected aspects of lived experience. Stoller claims that textual research practices disregard bodily experiences. Pollock makes the argument that textual research is limited to a single point of view. Foster believes that textuality discounts the body's ability to enact meaning. As a response to these limitations, Stoller suggests more descriptive ways of writing that include bodily feelings, sensations, and movements. Pollock suggests ways of writing that allow for duplicity, doubleness, and simulation-writing that speaks as writing and not as a means for understanding meaning-by providing specific advice on how to make writing 
perform. Finally, Foster calls for writing practices that include the body as an active agent of research. These scholars contend that writing in the social sciences should be more embodied and active. Instead of engaging in inscriptive practices, we should be doing writing. Furthermore, effective scholarship, they believe, should be relabeled moving writing. They advocate writing styles, techniques, and strategies that engage, perform, animate, incorporate, and move. Stoller, Pollock, and Foster definitely lay down the challenge to present more visceral texts. However, we are not sure if these messier texts satisfy our original unease at representing movement through writing. Is the crisis of representation now solved?

\section{CONCLUSION}

Certainly, we endorse more evocative social science writing practices that present closer approximations of lived experience, but we still believe that this is only a partial solution to the limitations of textual representations. As a way of explaining how we feel, imagine that a museum has rearranged its display of a tribal dance performance based on the same principles governing the advent of new ways of writing research. Traditionally, a museum would present an exhibition of tribal dance through photographs organized by written captions. The written descriptions and photographs then would become the objects of research. However, when we step inside the museum now, instead of the performance being inscribed into pictures and texts, we encounter a videotape that captures the sounds, the movement, the environment, the feeling, and the color of the original performance. There is even a researcher pictured in the videotape who explains the performance and briefly participates in the dizzying movement ritual. In addition, the performers also speak. We hear them in their broken English explain their feelings while performing. For an added effect, the video uses multiple camera techniques to create a rich context for the performance. Finally, we are invited to interact with the performance through computer simulations that recreate the sounds of native birds, play more music representative of the region, and locate exactly where the performance is taking place on a digital global map.

Although this display is definitely more stimulating and illuminating and opens itself up to more varied interpretations about the performance, it is nevertheless a museum display transplanted from the field to serve an entirely different purpose from its original intention. Collated by the museum personnel to please, educate, and entertain, this exhibition through vision and sound only captures aspects of the performance. It is still, in essence, a textual representation of a movement experience. Likewise, artistically shaped and styled written research still preserves movement in a text. Therefore, we do not believe that it is possible for new writing practices to go 
beyond textuality. Instead, we wonder whether we are expecting too much from written research. Although writing can invite multiple interpretations, provide rich descriptions, and engage a reader's imagination, it still primarily serves to communicate meanings. Why should we expect writing to move, embody, or perform? In the same vein, why should we expect movement to communicate? Naturally, gestural movements do communicate, and obviously, all our movements are inscribed with intricate societal meanings, but must movement always be understood as a means for communication? Can it exist for its own sake?

One way to formulate a response to these questions is to consider how movement is sensed. Movement is perceived by proprioceptors in our muscle tissues and ligaments. These proprioceptors register the location of our body parts in space. Movement experiences, therefore, are mainly about one's self. We communicate with others through hearing and vision and translate these perceptions into speech and writing. We can also communicate our movement experiences through language, but conveying actual movement sensations requires perceptions that are different from seeing and hearing. However, we rely so strongly on our visual and auditory senses that we have tremendous difficulty identifying messages from our kinesthetic sense. Perhaps this indicates an increasing shift into things textual, in which movement will increasingly become an object of reflection. For example, when our attention is diverted from how it feels to move, we become completely unaware of our bodies in space. This makes it difficult for us to remember various movement sequences or combinations or to learn new movements without the help of written instructions. As a result, we might become a culture of bad movers or nonmovers. We hardly move spontaneously as it is. At a recent rock concert we attended in New Zealand, only the most dedicated fans jumped up and down to the pulsating sounds. Even Pirkko, the dancer, just tapped her foot quietly. Furthermore, we point enviously at African American's, Maori's, or other native people's "natural" ability to dance or do sports, whereas we are born with stiff hips and two left feet. With centuries' emphasis on textuality, have we perhaps forgotten how to appreciate our kinesthetic knowledge?

Although our kinesthetic sense may not be used in the same way as language-to communicate-it does provide us with knowledge. However, the problem is that we have difficulties demonstrating or sharing this knowledge through language or writing. As a result, movement is not recognized as valuable knowledge. How should we, then, present this knowledge? This is a very puzzling question, and we as researchers trained in the Western tradition find it very difficult to provide an answer to it. To tackle this question would mean challenging the entire notion of research as written communication. Clandinin and Connelly (1994) offer an entry point when they argue that researchers' eagerness to translate every experience, not only bodily ones, into text stems from our recent academic traditions that privilege text over 
any other kind of expression or meaning. "These dispositions," they claim, "are based on the argument that experience cannot speak for itself and the focus needs to be on the meaning contained in texts and the forms by which they are constructed" (p. 415). In the current research climate, in which writing is privileged, experiences like movement are seen primarily as data waiting to be analyzed. However, what if we focused on the experience as an end in itself instead of a means for research and thus omitted the cumbersome translation from experience to written text? What kind of research would result?

At this point, we find it almost impossible to imagine how experience alone could replace communication as the premise of research. However, if we consider that writing and reading are also solitary experiences and therefore do not necessarily guarantee that the author's intended meanings have been communicated, perhaps it is possible to conceptualize experiences felt during dancing or running as knowledge production per se. Even if we do not communicate these experiences through writing, this embodied knowledge can certainly help us to understand ourselves as human beings. Furthermore, we consider understanding our bodies and movement patterns as an essential part of our existence.

Although experience as research might seem too utopian in today's highly textual academic environment, writing this article has helped us to at least question or consider some taken-for-granted notions of research. In addition, we are no longer happy to endorse the ever-popular new ways of writing circulating within the social sciences as a final solution to the crisis of representation and issues of inscription and incorporation. Therefore, to go beyond the assumption that movement can only be an object used for textual analysis, we propose the beginning of a dialogue that makes us think more critically about the limitations of written research. By this, we are not suggesting that movement or the body exist outside of discourse and can thus reveal an essential core that language cannot. On the contrary, we believe that both language and movement are deeply influenced by a range of social practices. However, if we entirely ignore our physicality, there is the danger that we might begin to consider language as essential, that is, a core that all else can be derived from and the only true way to understand what it means to be human.

Although questioning the dominant use of language as a tool for interpretation might seem preposterous at a time when verbal and written communication are so privileged, we believe that the prominence of this type of research has to be challenged. At the very least, this skepticism gets us to recognize where the power lies within the research community and how we may be limited by it. We must continually remind ourselves that written research is a tradition only; neither is it a fixed practice nor must it alone equal what research can be. 


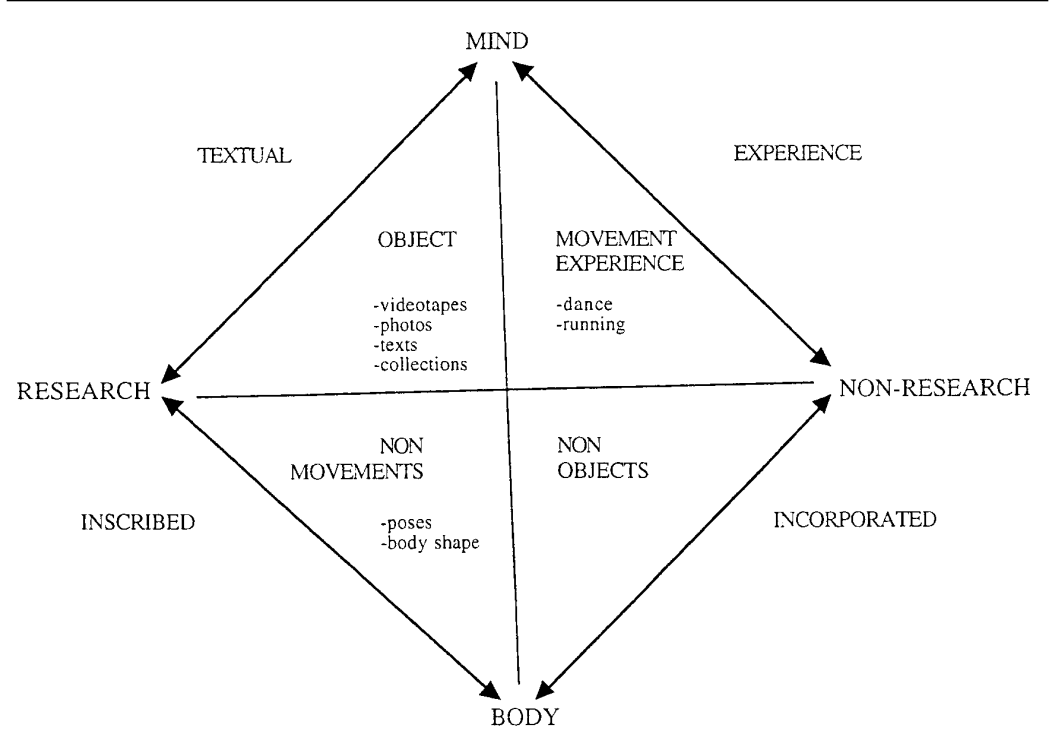

Figure 1: Movement Research Diagram

\section{NOTE}

1. Following the notion that sets of binary oppositions create our ideological consciousness in Western society, we drew a diagram of the field of movement research. Movement research in this diagram is located within two initial oppositions, research and nonresearch, and mind and body, that then generate other meaning fields around them: textual, inscribed, experience, and incorporated. Approaches to understanding movement, then, oscillate between these different fields and are classified as either research or nonresearch. In our discussion, we aim to demonstrate that in order to be considered research, movement as a nonobject has to travel from its body-incorporated field and cross the horizontal axis into the experience field. This means that it is now more closely connected to the mind. However, experience still has to be converted into an object to become research. To do this, it must cross the vertical axis of the diagram and enter the textual field. Thus, to count as acceptable research, movement has traveled across the diagram.

Research on the body can follow a different path within the diagram. If the body is conceptualized as nonmoving, to become research, it must simply cross the horizontal axis into the textual field. It is now an object that is available for researchers' inquiring gaze. As a visible object, it is now possible to read the body's societal meanings and turn them into written research.

We interpret that the new writing techniques advocated by Stoller (1994), Pollock (1998), and Foster (1995) have aimed to move from the textual field across the vertical 
axis of the diagram into the experience field. These writing techniques, however, seem unable to cross the diagram diagonally and go directly into the incorporated field. Therefore, they remain very much aligned with the mind. This might be one of the reasons why we are still skeptical about their ability to capture movement experience.

By drawing this diagram, we have aimed to demonstrate how our Western notions of research rely on binary, hierarchical oppositions. We aim to challenge this premise as a construction that privileges the conceptualization of certain kinds of research, which at present excludes the incorporated body. We feel, like numerous other researchers, that the moving body constitutes an important part of our understanding of what it means to be human. Therefore, it is necessary to continually deconstruct the influence that binaries have on us.

\section{REFERENCES}

Adair, S. (1992). Women and dance: Sylphs and sirens. New York: New York University Press.

Barth, J. (1956). The floating opera. London: Secker \& Warburg.

Baudrillard, J. (1997). The system of objects. London: Verso.

Birrell, S., \& Cole, C. L. (1994). Women, sport, and culture. Champaign, IL: Human Kinetics.

Blumenfeld-Jones, D. S. (1995). Dance as mode of research representation. Qualitative Inquiry, 4, 391-401.

Bordo, S. (1993). Weight, feminism, Western culture, and the body. Los Angeles: University of California Press.

Bruce, T. (1998). Postmodernism and the possibilities for writing "vital" sports texts. In G. Rail (Ed.), Sport and postmodern times (pp. 3-19). Albany: State University of New York Press.

Clandinin, J., \& Connelly, M. (1994). Personal experience methods. In N. K. Denzin \& Y. S. Lincoln (Eds.), Handbook of qualitative research (pp. 413-427). Newbury Park, CA: Sage.

Clifford, J. (1988). The predicament of culture: Twentieth-century ethnography, literature, and art. Cambridge, MA: Harvard University Press.

Cole, C. L., \& Hribar, A. (1995). Celebrity feminism: Nike style: Post-Fordism, transcendence, and consumer power. Sociology of Sport Journal, 12, 347-369.

Connerton, P. (1989). How societies remember. Cambridge, UK: Cambridge University Press.

Cooper Albright, A. (1997). Choreographing difference: The body and identity in contemporary dance. Hanover, NH: Wesleyan University Press.

Daly, A. (1992). Dance history and feminist theory: Reconsidering Isadora Duncan and the male gaze. In L. Senelick (Ed.), Gender and performance (pp. 240-255). Hanover, NH: University Press of New England.

Davis, L. (1997). The swimsuit issue: Hegemonic masculinity in Sports Illustrated. Albany: State University of New York Press.

Dempster, E. (1988). Women writing the body: Let's watch a little how she dances. In S. Sheridan (Ed.), Grafts: Feminist cultural criticism (pp. 35-54). London: Verso.

Denison, J. (1996). Sport narratives. Qualitative Inquiry, 2, 351-362. 
Denzin, N. K. (1997). Interpretive ethnography: Ethnographic practices for the 21st century. Newbury Park, CA: Sage.

Desmond, J. (1994). Embodying difference: Issues in dance and cultural studies. Cultural Critique, 26, 33-63.

Duncan, M. C. (1990). Sports photographs and sexual difference: Images of women and men in the 1984 and 1988 Olympic games. Sociology of Sport Journal, 7, 22-43.

Duncan, M. C. (1994). The politics of women's body images and practices: Foucault, the panopticon, and Shape magazine. Journal of Sport E Social Issues, 18, 48-65.

Foster, S. L. (1986). Reading dancing: Bodies and subjects in contemporary American dance. Berkeley: University of California Press.

Foster, S. L. (1995). Choreographing history. In S. L. Foster (Ed.), Choreographing history (pp. 3-21). Bloomington: Indiana University Press.

Hall, M. A. (1996). Feminism and sporting bodies: Essays on theory and practice. Champaign, IL: Human Kinetics.

Jameson, F. (1981). The political unconscious: Narrative as a socially symbolic act. Ithaca, NY: Cornell University Press.

Kagan, E., \& Morse, M. (1988). The body electronic: Aerobic exercise video. The Drama Review, 32, 164-180.

Kirschenblatt-Gimblett, B. (1998). Destination culture: Tourism, museums, and heritage. Berkeley: University of California Press.

Koritz, A. (1996). Re/moving boundaries: From dance history to cultural studies. In G. Morris (Ed.), Moving words: Rewriting dancing (pp. 88-103). New York: Routledge.

Krieger, S. (1991). Social science and the self: Personal essays on an art form. New Brunswick, NJ: Rutgers University Press.

Langer, S. (1953). Feeling and form. New York: Scribner.

Lather, P., \& Smithies, C. (1997). Troubling the angels: Women living with HIV/AIDS. Boulder, CO: Westview.

Lenskyj, H. (1998). "Inside sport" or "on the margins"?: Australian women and the sport media. International Review for the Sociology of Sport, 33, 19-32.

Loy, J., Andrews, D., \& Rinehart, R. (1993). The body in culture and sport. Sport Science Review, 2, 69-91.

Maguire, J., \& Mansfield, L. (1998). "No-body's perfect:" Women, aerobics, and the body beautiful. Sociology of Sport Journal, 15, 109-137.

Markula, P. (1995). Firm but shapely, fit but sexy, strong but thin: The postmodern aerobicizing female bodies. Sociology of Sport Journal, 12, 424-453.

McFee, G. (1994). Understanding dance. London: Routledge.

McKay, J., \& Middlemiss, I. (1995). "Mate against mate, state against state:" A case study of media constructions of hegemonic masculinity in Australian sport. Masculinities, 3, 28-45.

Messner, M. A., \& Sabo, D. S. (1990). Sport, men, and the gender order: Critical feminist perspectives. Champaign, IL: Human Kinetics.

Novack, C. J. (1995). The body's endeavors as cultural practices. In S. L. Foster (Ed.), Choreographing history (pp. 177-184). Bloomington: Indiana University Press.

Phelan, P. (1993). Unmarked: The politics of performance. London: Routledge.

Pirinen, R. M. (1997). The construction of women's position in sport: A textual analysis of articles on female athletes in Finnish women's magazines. Sociology of Sport Journal, 14, 290-301.

Pollock, D. (1998). Performing writing. In P. Phelan \& J. Lane (Eds.), The ends of performance (pp. 73-103). New York: New York University Press. 
Richardson, L. (2000). New writing practices in qualitative research. Sociology of Sport Journal, 17, 5-20.

Rinehart, R. (1998a). Fictional methods in ethnography: Believability, specks of glass, and Chekhov. Qualitative Inquiry, 4, 200-224.

Rinehart, R. (1998b). Ska8ing. Waikato Journal of Education, 4, 55-63.

Rintala, J. (1991). The body-mind revisited. Quest, 43, 260-279.

Sherlock, J. (1991). Culture, ideology, gender and dance. Society and Leisure, 14, 543-556.

Sparkes, A. C. (1996). The fatal flaw: Narrative of the fragile body-self. Qualitative Inquiry, 2, 463-494.

Stoller, P. (1994). Embodying colonial memories. American Anthropologist, 96, 634-648.

Sudwell, M. (1999). The body bridge. In A. C. Sparkes \& M. Silvennoinen (Eds.), Talking bodies: Men's narratives of the body and sport (pp. 13-28). Jyväskylä, Finland: SoPhi.

Theberge, N. (1991). Reflections on the body in the sociology of sport. Quest, 43, 123-134.

Thomas, H. (1996). Do you want to join the dance?: Postmodernism/poststructuralism, the body, and dance. In G. Morris (Ed.), Moving words: Rewriting dancing (pp. 63-87). New York: Routledge.

Tiihonen, A. (1994). Asthma: The construction of the masculine body. International Review for Sociology Sport, 29, 51-61.

Trinh, T.M.-H. (1989). Woman, native, other: Writing postcoloniality and feminism. Bloomington: Indiana University Press.

Trujillo, N. (1995). Machines, missiles, and men: Images of the male body on ABC's Monday Night Football. Sociology of Sport Journal, 12, 403-423.

Tsang, T. (2000). Let me tell you a story: A narrative exploration of identity in highperformance sport. Sociology of Sport Journal, 17, 44-59.

Wallace, D. F. (1999). Brief interviews with hideous men. New York: Little, Brown.

White, P. G., \& Gillett, J. (1994). Reading the muscular body: A critical decoding of advertisements in Flex Magazine. Sociology of Sport Journal, 11, 18-39.

Yeates, H. (1995). The league of men: Masculinity, the media \& rugby league football. Media Information Australia, 75, 35-45.

Pirkko Markula studied sport sociology and dance at the University of Illinois at Urbana-Champaign. She is with the Department of Leisure Studies at the University of Waikato, New Zealand. She is currently examining Western notions of the body in women's fitness and dance.

Jim Denison is with the Department of Leisure Studies at the University of Waikato, where he teaches courses related to psychology, sport, and narrativity. He is currently completing a novel on running. 